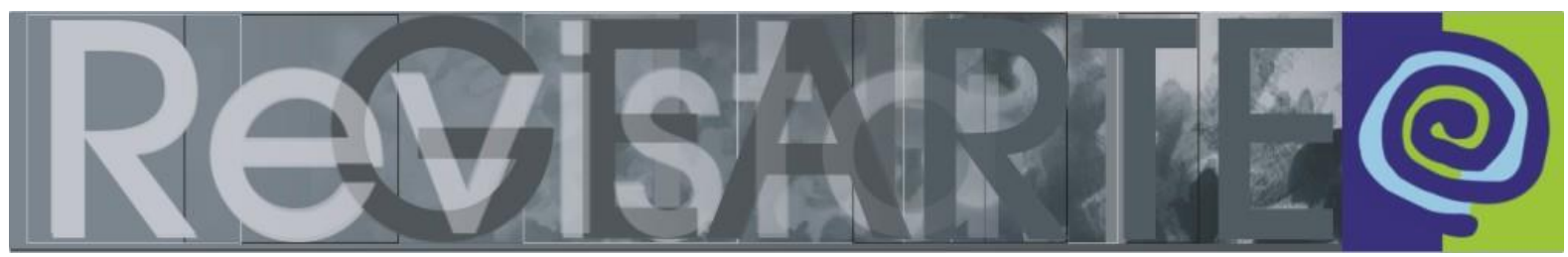

ISSN 2357-9854

\title{
Arte contemporânea e ensino da arte: contextos de produção de sentido
}

\author{
Rejane Reckziegel Ledur (Universidade Luterana do Brasil — ULBRA, Canoas/RS, Brasil)
}

RESUMO - Arte contemporânea e ensino da arte: contextos de produção de sentido - $O$ artigo discute os desafios da educação atual, a partir do olhar e da experiência estética com a arte contemporânea no contexto escolar. Tem como referência duas pesquisas acadêmicas (LEDUR, 2005, 2013) em relação à produção de sentidos na interação com a arte contemporânea de professores de arte e alunos do Ensino Fundamental de uma rede municipal de ensino. Autores como Cauquelin (2005), Bourriaud (2009), Bauman (1998, 2007), Sibilia (2012) e Acaso (2009) fundamentam as reflexões referentes às transformações da pós-modernidade; as análises da experiência estética partem dos estudos de Bakthin, Dewey e da semiótica greimasiana. Ao considerar a interação com a arte contemporânea como uma experiência sensível e inteligível, observou-se a recorrência de sentidos específicos apoiados em princípios fundamentais da experiência estética com a arte contemporânea. A compreensão construída em torno da percepção dos sentidos, produzidos pelos alunos na interação com a arte contemporânea, foi representada por meio do "quadrado semiótico". Nesse esquema, salientam-se os regimes de contemplação, interrogação, significação e percepção, como resultantes da apreensão estética da arte contemporânea.

PALAVRAS-CHAVE

Experiência estética. Produção de sentido. Arte contemporânea.

ABSTRACT - Contemporary art and art education: contexts of meaning production - The article discusses the challenges of present day education, considering the ability to see and the experience with contemporary art at the school context. It has as its reference the academic research (LEDUR, $2005,2013)$ in relation to the meaning producedin interaction with contemporary art by teachers and students of Elementary Education from public schools assisted by the city. Authors like Cauquelin (2005), Bourriaud (2009), Bauman (1998, 2007), Sibilia (2012) and Acaso (2009) underlie the thinking on the transformation of post-modernity; the analysis of aesthetic experience are based on studies by Bakhtin, Dewey and greimasian semiotics. As the interaction with contemporary art was considered as a sensible and intelligible experience, it was observed the recurrence of specific meanings grounded in basic principles from the esthetic experience with contemporary art. The comprehension built around the perception of meanings, which were produced by the students in the interaction with contemporary art, was represented using the semiotic square. In this scheme, modes of contemplation, questioning, meaning and perception were pointed out as a result of contemporary art apprehension.

KEYWORDS

Esthetic experience. Meaning production. Contemporary Art.

\section{Os desafios da educação contemporânea}

A escola, como uma instituição social inserida num contexto pós-moderno, ainda mantém uma estabilidade em relação ao paradigma tradicional e moderno. Indiferente à classe social, hoje, os alunos estão inseridos numa cultura pós-moderna, mediada pelos avanços tecnológicos, constituindo-se através das redes sociais de comunicação, interagindo com diferentes linguagens, contextos e intertextos, que 
rompem com o paradigma moderno construído em torno de narrativas fixas, lineares e históricas. Na atualidade, quase todas as informações estão disponíveis e são acessadas pelos meios tecnológicos de comunicação.

Os reflexos desse descompasso entre as transformações na sociedade e a escola se tornam visíveis quando nos defrontamos, por exemplo, com a indiferença e a falta de sentido por parte dos estudantes brasileiros em relação aos conhecimentos e conteúdos enfatizados nas disciplinas escolares. A indisciplina e os altos índices de evasão escolar, observados em todos os níveis de ensino, sinalizam para uma prática de ensino descontextualizada da vida cotidiana.

A pesquisadora Paula Sibilia (2012) ao discutir sobre a crise na educação reflete sobre a obsolência da escola na atualidade, considerando-a uma máquina antiquada para dar conta dos corpos e das subjetividades das crianças e jovens de hoje. Ao fazer uma genealogia desta instituição, que foi criada na modernidade, aponta para inúmeros e complexos fatores que contribuem para falta de sintonia entre os componentes e modos de funcionamento históricos da escola com os "novos modos de ser e estar no mundo que emergem e se desenvolvem respondendo às exigências da contemporaneidade" (SIBILIA, 2012, p. 47).

As crianças e os jovens que são nativos digitais abraçam os dispositivos eletrônicos e se envolvem com eles de maneira mais visceral e naturalizada. Por isso, não é estranho considerar que "a sala de aula escolar tenha se convertido em algo terrivelmente 'chato', e a obrigação de frequentá-la implique uma espécie de calvário cotidiano para os dinâmicos jovens contemporâneos" (SIBILIA, 2012, p. 65). Como consequência deste descompasso emergem a apatia e o escasso entusiasmo dos estudantes, que são sintomáticos da falta de sentido que as práticas escolares, centradas numa cultura letrada, suscitam nas novas gerações.

Nesse novo cenário, os professores também se sentem acuados e desafiados, não sabendo como agir diante das aflições que têm origem nos questionamentos acerca do significado do seu trabalho numa sociedade informacional e conectada por redes interativas. A autora entende que tanto a apatia como a hiperatividade são dois efeitos complementares da saturação contemporânea que resultam do contato com 
um meio evanescente, que não deixa marcas. No contexto atual, é importante tecer redes já que estas multiplicam as conexões e produzem uma densidade capaz de desacelerar a avalanche de informações, transformando-as em experiências.

Por isso o desafio é imenso nas novas circunstâncias: quando não se realizam em cada caso as operações capazes de sedimentar a experiência, detendo-se assim a multiplicação desenfreada, quando não se produz o pensamento capaz de produzir algum sentido, gerando subjetividades e encontros, resta apenas um excesso de estimulação que gira no vazio e se extingue no tédio. (SIBILIA, 2012, p. 91)

Sibilia (2012) considera que a escola contemporânea deve assumir o dificílimo compromisso de resistir ao fluxo de saturação que impede de pensar e agir mediante estratégias de fixação, pois não temos como fugir deste ambiente hiperestimulado e hiperestimulanteno qual vivemos. A autora entende que, entre verter energia na tentativa de bloquear esse contexto, somos desafiados como professores a conceber modos de se subjetivar, pensar e dialogar nessas condições.

Nesse mesmo rumo, Bauman (2007) reconhece, em tempos de modernidade líquida, que as relações entre cultura e educação também foram transformadas. Segundo o autor, vive-se hoje a síndrome da impaciência, atividades que antes eram feitas de bom grado pelos alunos, hoje são consideradas gastos de tempo e energia em vão. A educação que era um valor conquistado para toda vida, passou a ser um produto, uma coisa que se obtém e que perde seu valor rapidamente. Essas transformações deixam os educadores desnorteados em relação ao seu papel na escola diante do perfil dos alunos atuais.

En ningún otro punto de inflexión de la historia humana los educadores debieron afrontar un desafío estrictamente comparable con el que nos presenta la divisoria de aguas contemporáneas. Sencillamente nunca antes estuvimos en una situación semejante. Aún debemos aprender el arte de vivir en un mundo sobresaturado de información. Y también debemos aprender el aún más difícil arte de preparar a las próximas generaciones para vivir en semejante mundo. (BAUMAN, 2007, p. 46)

Portanto, a pós-modernidade pode ser olhada como um período impregnado de dúvidas e problemas de todas as ordens, mas também impregnado de possibilidades e mudanças que não podem ser desprezadas pela educação sem passar por uma análise detalhada. É urgente, então, repensar as concepções que fundamentam as práticas de ensino, o currículo e o funcionamento da escola diante 
das exigências atuais da sociedade da comunicação, mediada pelos meios tecnológicos de informação.

Neste contexto o campo da arte passa a ser um importante parâmetro de análise das questões que a pós-modernidade apresenta, tendo em vista que é um dos domínios particulares que, segundo Cauquelin (2005, p. 57), foram transformados pela "aura da comunicação". No contexto da sociedade contemporânea, a autora salienta a importância das práticas de comunicação que se tornaram uma necessidade social, sendo a tecnologia responsável pelos princípios essenciais de progresso e identidade, com a transmissão da informação em tempo real e em grande parte acessível para todos. Ressalta, no entanto, a importância da linguagem na construção e significação da realidade. Conforme a autora:

Se reconhecemos que a comunicação fornece à sociedade o elo indispensável a seu funcionamento, o papel da linguagem e seu exercício se tornam dominantes. É por intermédio da linguagem que se estruturam não somente os grupos humanos, mas ainda a apreensão das realidades exteriores, a visão do mundo, sua percepção e sua ordenação. (CAUQUELIN, 2005, p. 63)

A arte contemporânea recobre as experimentações mais diversas que denotam uma mudança conceitual e estética nas práticas artísticas, provocando uma mudança na recepção das obras. $\mathrm{Na}$ atualidade, as propostas artísticas caracterizam-se muito mais por serem acontecimentos e experimentos em que o espectador já está posto na obra e é provocado a atuar como participante da construção do sentido por meio da recepção.

Nicolas Bourriaud (2009), ao examinar o complexo jogo da arte contemporânea, busca perceber quais são os interesses da arte na atualidade e suas relações com a sociedade, a história e a cultura. $O$ autor observa, assim como Cauquelin, o papel da comunicação nos dias atuais, que restringe os contatos humanos dentro de espaços de controle, decompondo o vínculo social em elementos distintos. E considera que a atividade artística aparece hoje como um campo fértil de experimentações sociais, que busca "abrir algumas passagens obstruídas, pôr em contato níveis de realidade apartados" (BOURRIAUD, 2009, p. 11). 
Esse mesmo autor considera que um artista, ao produzir as obras, destina os seus trabalhos para seus contemporâneos e que a obra de arte é uma oportunidade para promover uma experiência sensível baseada na troca, para ele "Hoje, o que estabelece a experiência artística é a co-presença dos espectadores diante da obra, quer seja afetiva ou simbólica" (BOURRIAUD, 2009, p. 80). Salienta ainda que esta experiência não deriva mais da simples "percepção ocular", pois o espectador "traz todo o seu corpo, sua história e seu comportamento e não mais uma simples presença física abstrata" (BOURRIAUD, 2009, p. 83).

O curador também destaca que a possibilidade de uma arte relacional, voltada para a esfera das interações humanas e seu contexto social, resulta, principalmente, de uma cultura urbana mundial e atesta uma inversão radical dos objetivos estéticos, culturais e políticos, postulados pela arte moderna. A aplicação do modelo de cidade influenciou todos os fenômenos culturais, mostrando através da mudança de função e do modo de apresentação das obras de arte uma urbanização crescente da experiência artística. Em relação à obra contemporânea afirma: "agora ela se apresenta como uma duração a ser experimentada, como uma abertura para a discussão ilimitada", e que esse regime de encontro casual e intensivo criou práticas artísticas embasadas na subjetividade que "tem como tema central o estar-junto, o 'encontro' entre o observador e quadro, a elaboração coletiva do sentido" (BOURRIAUD, 2009, p. 20-21).

A obra de arte ocupa, assim, um lugar de interstício social no sistema global da economia que rege a sociedade contemporânea, tanto no campo simbólico ou material. Para Bourriaud, o interstício caracteriza-se por ser um espaço de relações humanas que sugere outras possibilidades de troca além daquelas vigentes no sistema global. Nesta perspectiva, a obra de arte possibilita essas experiências e propõe "novas possibilidades de vida". Segundo o autor:

É exatamente esta a natureza da exposição de arte contemporânea no campo do comércio das representações: ela cria espaços livres, gera durações com um ritmo contrário ao das durações que ordenam a vida cotidiana, favorece um intercâmbio humano diferente das 'zonas de comunicação' que nos são impostas. (BOURRIAUD, 2009, p. 22-23) 
Ainda conforme Bourriaud, a estética relacional inscreve-se numa tradição materialista e constitui uma teoria da forma, em que a forma pode ser considerada como uma estrutura que apresenta as características de um mundo, uma unidade coerente. Toda obra é, portanto, modelo de um mundo viável, pois permite o encontro fortuito de elementos separados: "A arte mantém juntos momentos de subjetividade ligados a experiências singulares" (BOURRIAUD, 2009, p. 27).

Por isso, o autor considera que a forma da obra contemporânea extrapola sua forma material, sendo "um elemento de ligação, um princípio de aglutinação dinâmica". E que a forma artística só se constitui na dimensão do diálogo, no olhar do outro: "a forma só assume sua consistência (e adquire uma existência real) quando coloca em jogo interações humanas; a forma de uma obra de arte nasce de uma negociação com o inteligível que nos coube" (BOURRIAUD, 2009, p. 30).

O aspecto da estética relacional destacado por Bourriaud é muito presente na arte contemporânea. $O$ viés apresentado por ele não consegue abranger todas as obras, mas apresenta uma possibilidade de leitura para muitas produções artísticas que visam à interação com o outro, no caso o espectador. São vias de acesso que nos conduzem pelo campo simbólico da arte e que nos permitem compreender a complexidade das relações e conceitos que estão subjacentes na arte contemporânea, ao envolver as instâncias do pensamento, da criação e da fruição artística.

Celso Favaretto (2010) sintetiza a investigação sobre o sentido da arte que resultou "da radicalidade moderna, emblematizada nas propostas da vanguarda":

\begin{abstract}
$\mathrm{Na}$ arte surgida dessa atitude, patente nas atividades contemporâneas, as obras, os experimentos, as proposições de toda sorte, funcionam como interruptores da percepção, da sensibilidade, do entendimento; funcionam como um descaminho daquilo que é conhecido. Uma espécie de jogo com os acontecimentos, de táticas que exploram ocasiões em que o sentido emerge através de dicções e timbres, nas formas não nos conteúdos; uma viagem pelo conhecimento e pela imaginação: são imagens que procuram captar o tipo de deslocamento da subjetividade promovido pelas obras da arte. (FAVARETTO, 2010, p. 232)
\end{abstract}

Essa reflexão reforça o pensamento do ensino da arte voltar-se para a percepção das transformações e desconstruções da arte contemporânea como possibilidades de ressignificar o currículo e a prática docente, ao focar a atitude do 
artista como alguém a pensar o seu tempo, sem desconsiderar o passado, que busca na tradição o conhecimento a ser aprofundado e que se manifesta apoiado na sua própria experiência.

John Dewey enfatiza a experiência como uma negociação consciente entre o eu e o mundo, e ressalta que não há experiência mais intensa do que a proporcionada pela arte. Para o autor "a arte é a prova viva e concreta de que o homem é capaz de restabelecer, conscientemente e, portanto, no plano do significado, a união entre sentido, necessidade, impulso e ação que é a característica do ser vivo" (DEWEY, 2010, p. 93).

O autor considera a experiência como o "resultado, o sinal e a recompensa da interação entre organismo e meio que, quando plenamente realizada, é uma transformação da interação em participação e comunicação" (DEWEY, 2010, p. 8889). Assim, o estético é a qualidade especial que contrasta nitidamente a imagem formada sobre a experiência, diferenciando-a das experiências normais. A qualidade estética recebe um lugar e um status externo e é o que dá a unidade a uma experiência, "arredonda a experiência em sua completude e unidade, como emocional" (DEWEY, 2010, p. 118).

Dewey ressalta a importância da emoção como parte do eu interessado no movimento dos acontecimentos em direção a um desfecho desejado ou indesejado. Para o autor "a emoção é a força motriz e consolidante" (DEWEY, 2010, p. 120) que seleciona e confere uma unidade qualitativa nas e entre as partes distintas de uma experiência, agregando-Ihe um caráter estético.

Este é o desafio que a contemporaneidade apresenta para todos os professores que se dedicam ao projeto de ensinar e aprender. Entre ficarmos perplexos, aborrecidos, indignados com a ineficácia dos métodos pedagógicos tradicionais para com estudantes inseridos num contexto pós-moderno, María Acaso no livro La educación artística no son manualidades (2009), nos convida a construir novas práticas de ensino de arte e cultura visual.

De forma urgente, los que nos dedicamos a la ensenãnza y al aprendizage tenemos que acometer este desafío, especialmente los profesores de las 
disciplinas relacionadas con las artes y la cultura visual, porque en ese mundo sobresaturado de información, la mayoría de esa información és información visual. (ACASO, 2009, p. 173)

A autora apresenta uma reflexão sobre os desafios da educação, estabelecendo uma metáfora com a apreensão da arte contemporânea, em que o artista, a obra e o espectador equivaleriam ao professor, à experiência artística e ao estudante. Como na arte contemporânea assumimos a ideia que o espectador completa a obra, na educação também poderíamos dizer que o currículo, quem o termina ou o constrói, é o aluno.

Nesta perspectiva, ressalta Acaso (2009, p. 181), "o currículo deixa de ser um documento (ao fim e a cabo, um objeto) para passar a ser uma experiência. Experiência que nasce desta interação entre o aluno, verdadeiro eixo da aprendizagem, e outras entidades como textos, imagens ou pessoas ${ }^{1 "}$. Para tanto se faz necessário criar um conhecimento independente, baseado na revisão dos conteúdos que são apresentados oficialmente e relacionado com os conteúdos que se originam da vida real, fora do contexto educativo.

\section{A produção de sentidos na interação com a arte contemporânea}

A produção de sentidos na interação com a arte contemporânea é um tema que venho desenvolvendo como pesquisadora nos últimos anos. Provocada, incialmente, como espectadora ao ser confrontada com as obras contemporâneas em exposições de arte e cursos de formação, a experiência levou-me a desenvolver um percurso investigativo em torno da interação com as propostas artísticas que rompem com as linguagens tradicionais e modernas da arte, ao se apresentarem por meio de diferentes formas, temas, processos e materiais.

A arte contemporânea constitui-se como uma linguagem intertextual, multicultural, histórica, tecnológica, sincrética. As propostas artísticas da atualidade estão relacionadas com a vida cotidiana, social e cultural e rompem com as questões

Tradução nossa. 
da estética tradicional e moderna, solicitando uma forma diferente de interação e apreensão das obras.

O filósofo Arthur Danto (2006) descreve o sentimento de mal estar e rigozijo registrado em nossa consciência com a arte contemporânea que marca a sensibilidade histórica de não pertencer mais a uma grande narrativa. Para o autor "o contemporâneo é, de determinada perspectiva, um período de desordem informativa, uma condição de perfeita entropia estética. Hoje não há mais qualquer limite histórico. Tudo é permitido" (DANTO, 2006, p. 15).

Paralelamente, essas inquietações também foram me contagiando no meu papel de professora, transferindo para o campo da educação os mesmos questionamentos em relação aos desafios do ensino da arte a partir das desconstruções da pós-modernidade. Como professora de arte, atuando na formação continuada de professores numa rede pública de ensino, percebia no final da década de 90, a resistência dos professores em abordar a arte contemporânea no currículo escolar. Isso se evidenciava pela dificuldade que os professores tinham de entendêla, não conseguindo, assim, estabelecer propostas de ensino baseadas nessas obras e em seus artistas.

Essas experiências deflagraram um percurso investigativo sobre a apreensão estética da arte contemporânea que buscou, num primeiro momento, compreender os sentidos produzidos pelos professores de arte no encontro com a arte contemporânea. A pesquisa resultou na Dissertação de Mestrado, intitulada Professores de Arte e Arte Contemporânea: contextos de produção de sentido (UFRGS, 2005), em que estabeleci um diálogo com os professores de arte da Rede Municipal de Ensino de Canoas (RS) para perceber os sentidos produzidos no encontro dialógico com a arte contemporânea em eventos como a Bienal do Mercosul, Bienal de São Paulo e Mostra no Santander Cultural visitada por estes professores. Constituiu-se numa pesquisaintervenção, fundamentada nos referenciais teórico-metodológicos da Filosofia da Linguagem e da Teoria Estética de Bakthin, e no olhar da semiótica greimasiana para a análise da experiência estética dos professores com a arte contemporânea. 
A realização deste estudo permitiu conhecer os enunciados dos professores de arte em relação aos sentidos produzidos no acabamento estético das obras que dialogavam com os enunciados dos artistas, dos críticos, dos historiadores, enfim, teciam uma infinita rede de conexões de sentido, tendo como fio condutor a arte contemporânea.

$\mathrm{Na}$ época da pesquisa, os enunciados dos professores demonstraram diferentes compreensões responsivas no encontro dialógico com a arte contemporânea. As constatações levaram-me a concluir que a compreensão criadora estava relacionada com a identificação de códigos compatíveis do espectador com a obra na atitude responsiva, podendo apresentar construções de totalidades diferenciadas, conforme a relação que se estabelecia com a proposta artística. Os códigos observados diziam respeito às concepções, vivências e posicionamentos dos professores em relação à arte como manifestação artística. A atitude responsiva estava implicada diretamente com a predisposição do espectador para a resposta através da relação dialógica, podendo concordar, discordar, completar, adaptar, ou seja, concluir o evento estético.

Segundo Bakhtin (2000), a estesia como sentido é o nível mais profundo no acabamento estético e implica uma exotopia ${ }^{2}$ do espectador em relação à obra, é o encontro de duas consciências através do plano sensorial. A semiótica greimasiana possibilitou analisar os enunciados de estesia no encontro dos professores com a arte contemporânea, evidenciando momentos significativos que se caracterizaram tanto pela fratura, como acontecimento estético, quanto pelas escapatórias, consideradas como práticas estéticas construídas na vivência com as obras.

A pesquisa desencadeou novas problematizações em torno da apreensão da arte contemporânea, voltando-se, posteriormente, para a percepção das experiências estéticas dos alunos das séries finais do Ensino Fundamental na interação com as

2 O conceito de exterioridade ou exotopia na teoria estética de Bakhtin é um princípio básico da relação criadora, marcado por um estar exteriormente situado, no sentido espacial (de fora) e temporal (mais tarde). 
propostas artísticas da atualidade em visitas pedagógicas a 8 $8^{\text {a }}$ Bienal do Mercosul ${ }^{3}$ que foram oportunizadas no contexto escolar. Esse estudo foi concluído em 2013 e resultou na tese de doutorado Arte contemporânea e produção de sentidos no ensino da arte: a experiência estética dos alunos na Bienal do Mercosul sob o olhar da semiótica discursiva. Ambas as pesquisas foram realizadas no Programa de PósGraduação em Educação da Faculdade de Educação da Universidade Federal do Rio Grande do Sul/UFRGS, na linha de pesquisa Educação: Arte, Linguagem e Tecnologia.

Ao apoiar-me nos regimes de sentido e interação construídos por Landowski (2012), como uma grade de leitura para a análise dos dados desta pesquisa, fui percebendo a emergência de sentidos específicos de interação com a arte contemporânea. A recorrência destas situações nos relatos dos alunos permitiu agrupá-las em polaridades distintas que denotaram amparar-se em princípios fundamentais da experiência estética com a arte contemporânea. Essas diferentes significações relatadas pelos alunos foram traduzidas por expressões que sintetizavam a percepção particularizada da experiência de interação com a arte contemporânea, como: É lindo; É diferente; Não entendi; É interessante.

As expressões foram agrupadas em regimes de sentido e interação que buscaram dar conta da experiência estética com a arte contemporânea através das ações e princípios que as sustentam e formatam. A compreensão construída em torno da percepção dos sentidos produzidos pelos alunos na interação com a arte contemporânea foi representada por meio do "quadrado semiótico", em que se salientaram os regimes de contemplação, interrogação, significação e percepção.

3 A Bienal de Artes Visuais do Mercosul é uma mostra internacional de Arte Contemporânea que ocorre, desde 1997, em Porto Alegre e já consolidou o Rio Grande do Sul como um pólo cultural do Cone Sul. Promovida em anos ímpares pela Fundação Bienal do Mercosul, a mostra tem como público alvo os alunos da rede pública de ensino, disponibilizando ônibus para as visitas mediadas. O projeto educativo promove ações de formação, de mediação, distribui material educativo, oferece cursos, seminários, oficinas e publicações. 
Quadro 1 - Quadrado semiótico

\begin{tabular}{|c|c|}
\hline $\begin{array}{c}\text { Regime de sentido e interação: } \\
\text { CONTEMPLAÇÃO } \\
\text { Baseado na repetição de padrão: } \\
\text { É lindo! } \\
\text { Da ordem do distanciamento } \\
\text { Leitura de códigos }\end{array}$ & $\begin{array}{l}\text { Regime de sentido e interação: } \\
\text { INTERROGAÇÃO } \\
\text { Baseado na indefinição conceitual: } \\
\text { Não entendi. } \\
\text { Da ordem do perturbamento } \\
\text { Confronto de ideias }\end{array}$ \\
\hline $\begin{array}{c}\text { Regime de sentido e interação: } \\
\text { SIGNIFICAÇÃO } \\
\text { Baseado na construção de } \\
\text { significado: } \\
\text { É legal. É interessante } \\
\text { Da ordem do entendimento } \\
\text { Leitura visual }\end{array}$ & $\begin{array}{c}\text { Regime de sentido e interação: } \\
\text { PERCEPÇÃO } \\
\text { Baseado na compreensão } \\
\text { sensível: } \\
\text { É diferente. } \\
\text { Da ordem do sentir } \\
\text { Apreensão estética }\end{array}$ \\
\hline
\end{tabular}

Fonte: Ledur (2013, p. 203-204).

$\mathrm{Na}$ apreensão estética da arte contemporânea, a contemplação e a interrogação podem ser definidas como duas formas de não sentido: a primeira por estar fundada na continuidade e repetir um padrão tradicional de apreensão da arte, ao enfatizar que toda a arte tem por princípio a beleza, o que não se adapta à arte contemporânea; a segunda por caracterizar-se pela descontinuidade ao confrontar-se com algo estranho, que perturba, gera dúvida por não conseguir construir uma significação em torno do conceito de arte.

Em contrapartida, a significação e a percepção são duas formas em que o sentido é introduzido mediante a ultrapassagem de um ou de outro pólo das categorias anteriores (contínuo e descontínuo). A significação seria a negação da dúvida ao superar o efeito caótico que a arte contemporânea produz quando do perturbamento, harmonizando as partes que estavam em desordem, criando um todo de sentido que se sustente. A percepção, no entanto, consiste na negação do contínuo, do programado, dando margem ao aparecimento de uma certa fantasia ou do inesperado, ao sentir a obra e se surpreender pelas variações qualitativas que surgem no processo interativo.

A construção teórica, que resultou da experiência estética com a arte contemporânea, apresentada nessa pesquisa, foi fruto de uma investigação extensa 
e, ao mesmo tempo, intensa, caracterizada por um percurso pessoal de significação que, em todos os momentos, esteve permeado pelo sensível e inteligível, não se separando estes dois polos no processo de escrita da tese.

As experiências relatadas, assim como as análises e considerações, foram percepções recolhidas de um percurso investigativo fundamentado por um olhar teórico, em diálogo com as inquietações próprias de quem se aventura pelo caminho árduo e exaustivo de construir uma tese. Portanto não apresentam conceitos fixos e fechados, mas o processo de construção de uma significação em torno da experiência estética com a arte contemporânea, que podem ser aprofundados e revistos a partir de novas experiências e reflexões.

Ambas as pesquisas possibilitaram perceber as potencialidades da arte contemporânea como provocadora de sentidos, absorvendo e representando de forma visual e discursiva as características da pós-modernidade. Este percurso investigativo reforçou minha compreensão de que a arte contemporânea, como produção artística, tem potencial de transformação no currículo escolar ao desconstruir as práticas e conteúdos tradicionais de ensino, trazendo as questões da contemporaneidade para o contexto escolar. Também, ampliou a percepção do papel do professor de arte como potencializador da experiência estética na escola, ao ter como base um ensino de arte conectado com os desafios e as questões da arte na contemporaneidade.

As pesquisas realizadas em torno da produção de sentido dos professores e dos alunos na interação com a arte contemporânea, evidenciaram a potencialidade dessas experiências estéticas como promotoras de encontros e diálogos, de produção de pensamentos e reflexões sobre a vida. Além de possibilitar rupturas, perturbamentos e construção de novos saberes mediados pela arte.

Sendo assim, considero importante, em tempos de crise na educação, perceber as potencialidades e possibilidades que surgem das práticas de ensino conectadas com as questões contemporâneas da arte, que se apresentam como uma forma de poder ressignificar as práticas docentes obsoletas e arcaicas fundadas na transmissão vertical de conteúdos escolares. 


\section{Referências}

ACASO, Maria. La educación artística no son manualidades. Madrid: Catarata, 2009.

BAUMAN, Zigmunt. Los retos de la educación en la modernidad líquida. Barcelona: Gedisa, 2007.

BAUMAN, Zigmunt. O mal-estar da Pós-modernidade. Rio de Janeiro: Jorge Zahar Ed., 1998.

BOURRIAUD, Nicolas. Estética relacional. São Paulo: Martins Fontes, 2009.

CAUQUELIN, Anne. Arte contemporânea: uma introdução. São Paulo: Martins, 2005.

DANTO, Arthur C. Após o fim da arte: arte contemporânea e os limites da história. São Paulo: Odysseus Editora, 2006.

DEWEY, John. Arte como experiência. São Paulo: Martins Fontes, 2010.

FAVARETTO, Celso F. Arte contemporânea e educação. Revista Iberoamericana de Educación, Madrid, n. 53, p. 225-235. 2010. Disponível em: <www.rieoei.org/rie53a10.pdf>. Acesso em: 06 jan. 2013.

GREIMAS, Algirdas Julien. Da Imperfeição. São Paulo: Hacker Editores, 2002.

LANDOWSKI, Eric. ¿Habría que rehacer la semiótica? Contratexto 20, Universidad de Lima, p. 1227155, 2012b, Disponível em: <www2.ulima.edu.pe/Revistas/contratexto/index.htm>. Acessado em: 12 maio 2013.

LANDOWSKI, Eric. Aquém ou além das estratégias, a presença contagiosa. Documentos de Estudo Centro de Pesquisas Sociossemióticas, n. 3. São Paulo: Edições CPS, 2005. p.11-51.

LANDOWSKI, Eric. Interacciones arriesgadas. Lima: Universidad de Lima, Fondo Editorial, 2012.

LANDOWSKI, Eric. Para uma semiótica sensível. Educação \& Realidade, Porto Alegre, v. 30, n. 2, p. 93-106, jul./dez., 2005.

LEDUR, Rejane Reckziegel. Arte contemporânea e produção de sentidos dos alunos no ensino da arte: a experiência estética na Bienal do Mercosul sob olhar da semiótica. 2013. 234 f. Tese (Doutorado em Educação) - Faculdade de Educação, Universidade Federal do Rio Grande do Sul, Porto Alegre. 2013.

LEDUR, Rejane Reckziegel. Professores de Arte e Arte Contemporânea: contextos de produção de sentido. 2005. 166 f. Dissertação (Mestrado em Educação) - Faculdade de Educação, Universidade Federal do Rio Grande do Sul, Porto Alegre. 2005.

SIBILIA, Paula. Redes ou Paredes: a escola em tempo de dispersão. Rio de Janeiro: Contraponto, 2012.

\section{Rejane Reckziegel Ledur}

Doutora em Educação pela Universidade Federal do Rio Grande do Sul (UFRGS - 2013), Mestre em Educação pela UFRGS (2005) e Licenciada em Educação Artística com Habilitação em Artes Plásticas (UFRGS,1992). Professora do Curso de Artes Visuais e Pedagogia (EAD) da Universidade Luterana do Brasil (ULBRA). Professora da Rede Municipal de Ensino de Canoas (RS), atuando na Secretaria Municipal de Educação. Integra o Grupo de Pesquisa em Educação e Arte da UFRGS (GEARTE). Possui experiência nas áreas de Educação, Artes e Cultura, principalmente no ensino de Artes Visuais e na formação continuada de professores, desenvolvendo pesquisas nos seguintes temas: ensino de arte, produção de sentido, formação de professores e arte contemporânea.

E-mail: rejaneledur@gmail.com

Currículo: http://lattes.cnpq.br/9918984740294482

Recebido em 18 de julho de 2016 Aceito em 21 de agosto de 2016 